\title{
Princípios da política brasileira de segurança alimentar e o acordo sobre agricultura da OMC.
}

Rafael Rosa Cedro'

\section{Resumo}

Este artigo busca destacar que há uma contradição entre o objetivo pretendido pelo princípio geral do Acordo sobre Agricultura da Organização Mundial do Comércio (OMC) e aqueles definidos pela Lei Orgânica de Segurança Alimentar do Brasil (LOSAN), além de uma questão de injustiça para com os países em desenvolvimento. Enquanto a LOSAN enfatiza a importância da preservação da capacidade de os Estados Nacionais definirem as suas próprias políticas de incentivo à produção de alimentos, o Acordo sobre Agricultura da OMC leva todos os Estados Membros daquela organização a terem que relativizar o seu grau de soberania em termos alimentares. Essa relativização, no entanto, ocorre de forma desequilibrada em favor dos países desenvolvidos, especialmente Estados Unidos e União Europeia, que tiveram papel protagonista na redação do Acordo sobre Agricultura atualmente em vigor.

Palavras-chave: Soberania alimentar. Acordo sobre agricultura. OMC (Organização Mundial do Comércio).

\section{Introdução}

País de grandes contradições, o Brasil ainda apresenta, em pleno início de século XXI, situações de desenvolvimento socioeconômico incompatíveis com o seu nível de renda e capacidade produtiva. Ao mesmo tempo em que é celebrado

\footnotetext{
${ }^{1}$ Especialista em Políticas Públicas e Gestão Governamental e negociador em Genebra junto à OMC pelo Ministério do Desenvolvimento Agrário do Brasil. É mestrando em Direito e Políticas Públicas do Centro Universitário de Brasília. Foi pesquisador-visitante no Institut de Hautes Etudes Internationales et du Développement, em Genebra-Suíça. E- mail: rafael_cedro@yahoo.com.br
} 
como maior exportador líquido mundial de alimentos, o país convive com a fome e a pobreza, não apenas nas cidades, mas também no campo.

A política de Segurança Alimentar e Nutricional no país passou por relevantes transformações conceituais no passado recente. Esse processo culminou com a aprovação pelo Congresso Nacional da Lei Orgânica de Segurança Alimentar e Nutricional (LOSAN), Lei No 11.346, de 15 de setembro de 2006. A LOSAN está assentada fundamentalmente em dois princípios centrais norteadores: o direito humano à alimentação e a soberania alimentar.

A junção desses dois princípios foi estabelecida formalmente, colocando-se a preservação da soberania em termos de políticas públicas e decisões relativas ao sistema alimentar como um requisito para se alcançar o direito humano à alimentação. Essa forma como os dois princípios foram vinculados teve como objetivo principal garantir o espaço necessário, frente à crescente institucionalização do direito econômico internacional, para uma política de Estado que atacasse ao mesmo tempo as questões do combate à fome e o combate à pobreza rural.

Nesse contexto, é reservado um papel de destaque às ações públicas de incentivo à Agricultura Familiar, uma vez que esta é a responsável pela maior parte da produção dos alimentos que são consumidos internamente no Brasil e também em outros países em desenvolvimento. Essa importância é ainda amplificada quando se toma em consideração o potencial gerador de emprego e renda desse segmento socioprodutivo.

O Acordo sobre Agricultura da Organização Mundial do Comércio (OMC) foi instituído tardiamente, quando se analisa o seu surgimento no contexto da evolução do sistema internacional de regras para o comércio global. Dentre os princípios do Acordo sobre Agricultura da OMC, está centralmente a perspectiva de redução progressiva das ações e margens de política, dos Estados nacionais, que possam de alguma forma interferir com o funcionamento do livre-mercado.

O que este texto buscará destacar é que há uma contradição entre o objetivo pretendido pelo princípio geral do Acordo sobre Agricultura da OMC e aqueles definidos pela Lei Orgânica de Segurança Alimentar do Brasil, além de uma questão de injustiça para com os países em desenvolvimento. Enquanto a LOSAN enfatiza a importância de preservação da capacidade dos Estados nacionais de definirem as suas próprias políticas de incentivo à produção de alimentos, o Acordo sobre Agricultura da OMC leva todos os Estados Membros 
daquela organização a terem que relativizar o seu grau de soberania em termos alimentares. Essa relativização, no entanto, ocorre de forma desequilibrada em favor dos países desenvolvidos, especialmente Estados Unidos e União Europeia, que tiveram papel fundamental na redação do Acordo sobre Agricultura atualmente em vigor.

\section{Contexto recente e os princípios norteadores da política de segurança alimentar do Brasil}

Ainda que discutida de alguma forma no Brasil a cerca de 70 anos $^{2}$, e tendo sido objeto de experiências dispersas em termos de políticas públicas, especialmente nas últimas duas décadas, a temática da Segurança Alimentar, bastante demandada pelos movimentos populares e organizações da sociedade civil, entrou efetivamente na pauta de governo enquanto ação integrada a partir de 2003.

Naquele ano, teve início a implementação do Programa Fome Zero, nome popular com o qual foi batizada a Política de Segurança Alimentar e Nutricional do governo do presidente Luiz Inácio Lula da Silva ${ }^{3}$.

Os princípios que têm orientado a Política de Segurança Alimentar e Nutricional do Governo Lula, e que foram ratificados pela II Conferência Nacional de Segurança Alimentar e Nutricional, realizada em Olinda (PE), em março de 2004, configuram-se, em essência, como as perspectivas da alimentação como um direito humano fundamental e da soberania alimentar ${ }^{4}$.

\footnotetext{
${ }^{2}$ As primeiras reflexões sistemáticas sobre a temática da Segurança Alimentar e do Direito Humano à Alimentação datam da década de 1930, com o início dos estudos do pesquisador e professor Josué de Castro, autor de Geografia da Fome (1946) e A Geopolítica da Fome (1951), obras que tiveram grande repercussão internacional e que o credenciaram para o debate internacional sobre a questão da alimentação mundial enquanto um direito fundamental dos indivíduos e dos povos. IPEA; SEDH; MRE. A segurança alimentar e nutricional e o direito humano à alimentação no Brasil. Brasília: IPEA, 2002. p. 11. Um histórico mais abrangente da Segurança Alimentar e Nutricional e o direito humano à alimentação no Brasil pode ser visto na mesma obra, cap. 2, p. 11-18.

${ }^{3}$ TAKAGI, Maya. A implantação da política de segurança alimentar e nutricional no Brasil: seus limites e desafios. Campinas: Unicamp/IE, 2006. p. 2-4.

${ }^{4}$ CONFERÊNCIA NACIONAL DE SEGURANÇA ALIMENTAR E NUTRICIONAL, 2. mar. 2004, Olinda, PE. A construção da Política Nacional de Segurança Alimentar e Nutricional - Relatório final. Disponível em: <http://www.fomezero.gov.br/download/relatorio_final_IICNSAN.pdf>. Acesso em: 15 mai. 06.
} 
A união desses dois princípios tem como objetivo garantir não só o acesso universal e permanente pela população do país a alimentos de qualidade, respeitando-se a diversidade cultural e os aspectos de equidade de gênero e etnia. Visa também possibilitar a vinculação da estratégia de combate à fome ao incentivo à produção de alimentos internamente pela Agricultura Familiar ${ }^{5}$.

Em setembro de 2006, esses princípios básicos foram consolidados em uma Lei Orgânica de Segurança Alimentar e Nutricional(LOSAN), de forma a nortear o funcionamento mais permanente de um Sistema Nacional de Segurança Alimentar e Nutricional no país ${ }^{6}$.

Os principais acontecimentos que precederam essa consolidação em lei foram a ampla mobilização social associada a um momento de forte disposição política em relação à questão do combate à fome e à pobreza ${ }^{7}$. Essa bandeira foi exaltada já no discurso de posse do então presidente eleito, em $1^{\circ}$ de janeiro de 2003.

Naquele momento, foi institucionalizada a recriação do Conselho Nacional de Segurança Alimentar e Nutricional (doravante "CONSEA") 8 e o fortalecimento

${ }^{5}$ CONFERÊNCIA NACIONAL DE SEGURANÇA ALIMENTAR E NUTRICIONAL, 2., mar. 2004, Olinda, PE. A construção da política nacional de segurança alimentar e nutricional - Relatório final. Disponível em: <http://www.fomezero.gov.br/download/relatorio_final_IICNSAN.pdf $>$. Acesso em: 15 maio 06.

${ }^{6}$ BRASIL. Lei no 11.346 , de 15 de setembro de 2006. Cria o Sistema Nacional de Segurança Alimentar e Nutricional - SISAN com vistas em assegurar o direito humano à alimentação adequada e dá outras providências. Diário Oficial da União, Brasília, 18 set. 2006.

${ }^{7}$ TAKAGI, Maya. A implantação da política de segurança alimentar e nutricional no Brasil: seus limites e desafios. Campinas: Unicamp/IE, 2006. p. 1-5.

${ }^{8}$ O CONSEA foi reinstituído por meio da Medida Provisória № 103 , de $1^{\circ}$ de janeiro de 2003. Esse Conselho está diretamente vinculado à Presidência da República. A recriação do CONSEA se foi realizada com o objetivo de assessorar o Presidente da República na formulação de políticas e definição de diretrizes para a garantia do direito humano à alimentação. Outra função do CONSEA seria articular as ações governamentais para favorecer uma parcela da população desprovida de meios para atender suas necessidades básicas. BRASIL. Medida provisória no 103, de 01 de janeiro de 2003. Dispõe sobre a organização da Presidência da República e dos Ministérios, e dá outras providências. Diário Oficial da União, Brasília, 01 jan. 2003. 
de instâncias governamentais e de diálogo com a sociedade civil envolvidas na formulação e operacionalização da política de Segurança Alimentar do país ${ }^{9}$.

Por sua vez, o meio rural brasileiro apresenta, ainda no começo do século XXI, contradições de um país com elevada produção agrícola que, no entanto, se vê obrigado a enfrentar situações de pobreza extrema e fome no próprio campo. Situação esta que se adiciona a toda a pobreza verificável nas áreas urbanas.

Ao se analisar a distribuição de pessoas extremamente pobres, por situação de domicílio, nos cem municípios brasileiros com maior proporção de pobres, constata-se uma predominância de $62 \%$ destas pessoas no meio rural ${ }^{10}$. Estima-se adicionalmente que 1,6 milhões de um total de 4,1 milhões de famílias de agricultores e agricultoras familiares encontram-se abaixo da linha de pobreza. Por fim, um total de 18,9 milhões de pessoas no meio rural do país vivem em algum grau de insegurança alimentar ${ }^{11}$.

A conceituação formal de agricultor ou agricultora familiar no Brasil é dada pela Lei No 11.326, de 24 de julho de 2006, conhecida como "Lei da Agricultura Familiar" 12. Essa lei estabelece a conceituação oficial de Agricultura Familiar para ser utilizada do ponto de vista das políticas públicas nacionais. Os quatro elementos centrais definidos por essa lei para tal conceituação são: (i) não deter, a qualquer título, área maior do que

${ }^{9}$ Destaques para a criação do Ministério Extraordinário de Segurança Alimentar e Combate à Fome (MESA), posteriormente convertido em Ministério do Desenvolvimento Social e Combata à Fome (MDS), e a reestruturação e fortalecimento da Companhia Nacional de Abastecimento (CONAB), vinculada ao Ministério da Agricultura, Pecuária e Abastecimento, e do Ministério do Desenvolvimento Agrário (MDA) e seu Conselho Nacional de Desenvolvimento Rural Sustentável (CONDRAF).

${ }^{10}$ ROCHA, Sônia; ALBUQUERQUE, Roberto Cavalcanti de. Geografia da pobreza extrema e vulnerabilidade à fome. In: VELLOSO, João Paulo dos Reis; ALBUQUERQUE, Roberto Cavalcanti de (Org.). A nova geografia da fome e da pobreza. Rio de Janeiro: J. Olímpio, 2004. p. 38.

${ }^{11}$ BRASIL. Ministério do Desenvolvimento Agrário. Desenvolvimento agrário como estratégia: balanço MDA, 2003-2006. Porto Alegre: Nead, 2006. p. 26.

${ }^{12}$ De acordo com o seu Artigo $1^{\circ}$, ela estabelece os conceitos, princípios e instrumentos destinados à formulação das políticas públicas direcionadas à Agricultura Familiar e Empreendimentos Familiares Rurais. BRASIL. Lei no 11.326, de 24 de julho de 2006. Estabelece as diretrizes para a formulação da Política Nacional da Agricultura Familiar e Empreendimentos Familiares Rurais. Diário Oficial da União, Brasília, 25 jul. 2006. 
quatro módulos fiscais ${ }^{13}$; (ii) utilizar predominantemente mão-de-obra da própria família nas atividades econômicas do estabelecimento ou empreendimento; (iii) ter renda familiar predominantemente originada de atividades econômicas vinculadas ao próprio estabelecimento ou empreendimento; e (iv) a direção do estabelecimento ou empreendimento ser realizada pela própria família ${ }^{14}$.

Em termos quantitativos, a Agricultura Familiar responde por 76,9\% dos postos de trabalho no meio rural do Brasil, com um total de 13,8 milhões de pessoas ocupadas. Destaca-se que isso corresponde a 18,8\% da população economicamente ativa. Assim, a Agricultura Familiar caracteriza-se, não apenas como a principal fonte de ocupação no campo, como também no conjunto da economia do país ${ }^{15}$.

Apesar de ocupar apenas 30\% das terras e receber somente $25 \%$ do financiamento à produção, a Agricultura Familiar é responsável por 38\% do valor bruto total da produção agropecuária no Brasil ${ }^{16}$. Quanto à produção para fins alimentares, esse segmento produtivo responde por $70 \%$, ou seja, a maior parte dos alimentos que são consumidos pela população do país ${ }^{17}$. Dentre alguns dos principais alimentos da cesta básica nacional, a Agricultura Familiar responde pela produção interna de $85 \%$ da mandioca, $75 \%$ da cebola, $74 \%$ dos suínos, $70 \%$ do feijão, $70 \%$ do frango e $69 \%$ das hortaliças ${ }^{18}$. Assim, além de um importante peso socioeconômico, essa agricultura de pequena escala apresenta

${ }^{13} \mathrm{O}$ módulo fiscal é uma unidade de área variável, definida pelo INCRA, que representa a menor porção de terra numa localidade específica onde o estabelecimento rural se encontra a partir da qual uma família consegue extrair o seu sustento.

${ }^{14}$ BRASIL. Lei no 11.326 , de 24 de julho de 2006. Estabelece as diretrizes para a formulação da Política Nacional da Agricultura Familiar e Empreendimentos Familiares Rurais. Diário Oficial da União, Brasília, 25 jul. 2006.

${ }^{15}$ MOTA, Dalva Maria da; SCHMITZ, Heribert. Importância da agricultura familiar para a problemática da segurança alimentar. Estudos: revista da Universidade Católica de Goiás, Goiânia, v. 32, n. 2, p. 200, 2005.

${ }^{16}$ SOARES, Adriano Campolina. Multifuncionalidade da agricultura familiar. In: COMÉRCIO internacional, segurança alimentar e agricultura familiar. Rio de Janeiro: Rebrip / Action Aid, 2001. p. 91.

${ }^{17}$ BRASIL. Ministério do Desenvolvimento Agrário. Mais alimentos: um plano da agricultura familiar para o Brasil. Plano Safra da Agricultura Familiar 2008/09. Brasília: MDA, 2008. p. 3.

${ }^{18}$ Dados referentes à participação da Agricultura familiar na quantidade total produzida no país. Fonte: Secretaria de Agricultura Familiar do Ministério do Desenvolvimento Agrário, com base nas Tabulações Especiais do Censo Agropecuário 1995-96 do IBGE, elaboradas no âmbito do Projeto de Cooperação Técnica INCRA / FAO. 
uma relação bastante estreita com a questão da segurança alimentar e nutricional da população no Brasil.

Com relação ao conceito de Segurança Alimentar e Nutricional (doravante "SAN"), o debate no País vivenciou uma relevante divergência de concepção e princípios, especialmente entre os órgãos do governo, cujas competências legais estão mais diretamente relacionadas à produção de alimentos, ao abastecimento e à efetivação do direito humano à alimentação da população ${ }^{19}$. Essa divergência se tornava especialmente mais explícita quando a discussão transbordava para a arena das negociações dos tratados internacionais de comércio. Assim, ao longo do primeiro mandato do Governo Lula (2003-2006), houve uma disputa e uma grande indefinição em torno do conceito de SAN a ser efetivamente adotado do ponto de vista da formulação da política comercial externa.

Por um lado, o Ministério da Agricultura, Pecuária e Abastecimento (MAPA), durante todo aquele primeiro mandato, defendeu a adoção de um conceito de segurança alimentar que fosse amplamente baseado na abertura dos mercados mundiais alimentares ${ }^{20}$. Partindo desse ponto de vista, não haveria uma relação mais forte entre a garantia da segurança alimentar interna e o desenvolvimento de uma política de desenvolvimento rural que visasse fortalecer a Agricultura Familiar e a produção destinada ao mercado nacional. Partir-se-ia, então, do princípio de que qualquer necessidade alimentar, em tese, poderia ser suprida por meio do comércio com outros países. Assim, o Brasil poderia se especializar na produção de algumas poucas commodities, focando aquelas em que apresenta maior competitividade relativa ${ }^{21}$.

${ }^{19}$ Ministérios da Agricultura, Pecuária e Abastecimento (MAPA), do Desenvolvimento Agrário (MDA) e do Desenvolvimento Social e Combate à Fome (MDS).

${ }^{20}$ CONSELHO NACIONAL DE SEGURANÇA ALIMENTAR E NUTRICIONAL. Considerações de segurança alimentar e nutricional nas negociações internacionais integradas pelo Brasil - Relatório final. Brasília, 2005.

${ }^{21}$ Ibidem. A posição desse ministério sobre o tema tem base essencialmente na teoria econômica de cunho ortodoxo-liberal, que enfatiza a prevalência das forças de mercado sobre as interferências dos Estados-nações e suas políticas públicas no domínio socioeconômico. São contrários, portanto, a qualquer demanda no sentido de preservação de margens de soberania em termos alimentares. Uma síntese dos principais argumentos que dão embasamento a essa posição, dentre os quais a teoria Ricardiana das vantagens comparativas, pode ser encontrada na seção 1.3, intitulada "The gains from trade: theoretical perspectives", da publicação: FAO. Trade reforms and food security: conceptualizing the linkages. Roma: FAO, 2003. p. 13-16. 
De outro lado, estavam órgãos como o Ministério do Desenvolvimento Agrário, o Ministério do Desenvolvimento Social e Combate à Fome, e o Conselho Nacional de Segurança Alimentar e Nutricional, vinculado à Presidência da República, do qual fazem parte também um conjunto grande de entidades da sociedade civil ligadas à temática de segurança alimentar e à agricultura familiar ${ }^{22}$. Esse conjunto de entidades trabalhava com um conceito de segurança alimentar que tinha uma perspectiva forte de junção da concepção de direito humano à alimentação ao princípio da soberania alimentar. O princípio da soberania alimentar, da forma como discutido no Brasil, relaciona-se com o conceito levado a debate público pela Via Campesina ${ }^{23}$, em 1996, no processo da Cúpula Mundial da Alimentação em sua "Declaração de Soberania Alimentar"24.

Assim, para aquele grupo de atores, os diferentes povos deveriam ter o direto de definir suas próprias políticas e estratégias sustentáveis de produção, distribuição e consumo de alimentos ${ }^{25}$, sem obviamente, colocar em ameaça a soberania e a segurança alimentar das demais nações. O princípio da soberania alimentar

${ }^{22}$ A exemplo do Fórum Brasileiro de Segurança Alimentar e Nutricional (FBSAN), da Confederação Nacional dos Trabalhadores na Agricultura (CONTAG), da Federação dos Trabalhadores da Agricultura Familiar (FETRAF) e da Rede Brasileira pela Integração dos Povos (REBRIP), dentre outros.

${ }^{23}$ A Via Campesina é um movimento internacional autônomo que coordena organizações campesinas de médios e pequenos agricultores, trabalhadores agrícolas, mulheres e comunidades indígenas da Ásia, África, América e Europa. SíCOLI, Juliana Lordello. Pactuando conceitos fundamentais para construção de um sistema de monitoramento da SAN. [s.l.]: Instituto Polis, 2005. p. 7. Disponível em: <http://www.polis.org.br/download/65. pdf $>$. Acesso em: 25 maio 07.

${ }^{24}$ Segundo a introdução daquela declaração da Via Campesina, a "soberania alimentar é o direito de cada povo a definir suas próprias políticas agropecuárias e em matéria de alimentação, a proteger e regulamentar a produção agropecuária nacional e o mercado doméstico, no intuito de atingir objetivos de desenvolvimento sustentável, a decidir o grau em que querem ser autodependentes, a impedir que seus mercados sejam inundados por produtos excedentes de outros países que são vertidos no mercado internacional através da prática do dumping e a dar preferência às comunidades locais pescadoras com referência ao controle do uso e os direitos sobre os recursos aquáticos. A soberania alimentar não nega o comércio internacional, mas defende a opção de formular as políticas e práticas comerciais que melhor sirvam aos direitos da população a dispor de métodos e produtos alimentares inócuos, nutritivos e ecologicamente sustentáveis. A soberania alimentar é o direito dos povos, de seus Países ou Uniões de Estados a definir sua política agrária e alimentar, sem dumping perante terceiros países".

${ }^{25}$ CONSELHO NACIONAL DE SEGURANÇA ALIMENTAR E NUTRICIONAL. Lei de segurança alimentar e nutricional: conceitos. Brasília: CONSEA, 2006. p. 6. 
tem, portanto, como propósito, preservar, diante dos compromissos legais internacionais, a margem de política pública (policy space) ${ }^{26}$ necessária à implementação de ações do Estado no sentido de fomentar o desenvolvimento da produção interna de alimentos á medida que seja desejada pela sociedade nacional, respeitandose a cultura e os hábitos alimentares do país ${ }^{27}$.

Foi, então, apenas após longos debates internos que, em de 15 de setembro de 2006, instituiu-se a Lei Orgânica de Segurança Alimentar e Nutricional (LOSAN) do Bra, Lei No 11.346, na qual se consolidou formalmente a perspectiva da soberania alimentar como elemento fundamental, do ponto de vista do Estado brasileiro, para a consecução do atendimento do direito à alimentação da população brasileira ${ }^{28}$. Com os avanços de diálogo obtidos os longo de 2003 a 2008, começase então a observar o início de uma tradução mais efetiva das preocupações de desenvolvimento rural e de segurança alimentar na política comercial externa brasileira

${ }^{26}$ SOUTH CENTRE. Policy space for the development of the south. 'T.R.A.D.E. policy brief'. n. 1, 2005. Disponível em: <http://www.southcentre.org/info/ policybrief/01PolicySpace. pdf>. Acesso em 25 mai. 07.

${ }^{27}$ BELIK, Walter. Segurança alimentar: a contribuição das universidades. São Paulo: Instituto Ethos, 2003. p. 13. Adicionalmente, um conjunto de argumentos que enfatizam um papel estratégico que a Agricultura Familiar e a produção interna de alimentos têm para a consecução efetiva de uma política que garanta à população do país o atendimento ao seu direito humano à alimentação pode ser encontrado em: SOARES, Adriano Campolina. Multifuncionalidade da agricultura familar. In: COMÉRCIO internacional, segurança alimentar e agricultura familiar. Rio de Janeiro: Rebrip / Action Aid, 2001. p. 88-89; FAO. The State of Food Insecurity in the World 2006: Eradicating world hunger - taking stock ten years after the World Food Summit. Roma, 2006. p. 18-19; MOTA, Dalva Maria da; SCHMITZ, Heribert. Importância da agricultura familiar para a problemática da segurança alimentar. Estudos: revista da Universidade Católica de Goiás, Goiânia, v. 32, n. 2, p. 207-208, 2005. SOUTH CENTRE. Universal food security: issues for the south. Genebra, 1997. p. 68. Disponível em: <http://www.southcentre.org/publications/food/foodsec.pdf> Acesso em: 28 maio 07. DELGADO, Nelson Giordano; MALUF, Renato S. Comércio e desenvolvimento no acordo sobre agricultura da OMC: O Brasil e a proposta de uma caixa de desenvolvimento. In: Agricultura, meio ambiente e acesso ao mercado internacional: para quê e para quem? Rio de Janeiro: Action Aid, 2002. p. 32.

${ }^{28}$ CONSELHO NACIONAL DE SEGURANÇA ALIMENTAR E NUTRICIONAL. Lei de segurança alimentar e nutricional: conceitos. Brasília: CONSEA, 2006. 


\section{0 acordo sobre agricultura da OMC e as soberanias alimentares distorcidas}

O Acordo sobre Agriculturda Organização Mundial do Comércio foi firmado em abril de 1994. Esta foi a mesma ocasião em que foi criada a $\mathrm{OMC}^{29}$. Apesar da Organização ter sido estabelecida recentemente, ela traz consigo um histórico de quase cinco décadas anteriores, tendo incorporado e sucedido o Acordo Geral sobre Tarifas Aduaneiras e Comércio (GATT, na sigla em inglês).

Desde 1948, o sistema internacional de comércio vinha sendo regulado pelo GATT, que teve a sua evolução dada por meio de rodadas subsequentes de negociação. As primeiras rodadas englobavam essencialmente reduções de tarifas aduaneiras ${ }^{30}$. Com o passar do tempo, e com a continuidade das rodadas negociadoras, passou-se a incluir nas discussões e deliberações temas outros diversos, como medidas antidumping e medidas não-tarifárias.

A última rodada abrangente de negociações efetivamente concluída foi a Rodada Uruguai, ocorrida entre os anos de 1986 e $1994^{31}$. Nela, pela primeira vez, foi estabelecido um amplo acordo relativo à área agrícola. Esse acordo visava promover reduções nos subsídios à exportação, ampliar as oportunidades de acesso a mercados e diminuir o nível de subsídios à produção interna. ${ }^{32}$

O tema de agricultura já havia sido anteriormente submetido à apreciação no cenário internacional multilateral. No entanto, logo sofreu restri-

\footnotetext{
${ }^{29} \mathrm{O}$ acordo que instituiu a OMC foi firmado em abril de 1994, no âmbito da Rodada Uruguai. Este previu o início das atividades da organização para $1^{\circ}$ de janeiro de 1995. WTO. Uruguay Round Agreement: Marrakesh Declaration of 15 April 1994. Disponível em $<$ http://www.wto.org/ english/docs_e/legal_e/ marrakesh_decl_e.htm>. Acesso em: 05 fev. 2008.

${ }^{30}$ Barreiras tarifárias impostas pelos países à livre circulação do fluxo de comércio internacional.

${ }^{31}$ WORLD TRADE ORGANIZATION. The World Trade Organization in Brief. p. 3-4. Disponível em: <http://www.wto.org/english/res_e/doload_e/inbr_e.pdf >. Acesso em: 30 jan. 08.

${ }^{32}$ BARRAL, Welber (Org.). O Brasil e a OMC. 2. ed. Curitiba: Juruá, 2002. p. 95.
} 
ções por parte de países como os EUA e as Comunidades Europeias ${ }^{33}$. A objeção dos EUA, por exemplo, em aceitar diretrizes e regramentos mutuamente acordados entre os países para o comércio agrícola internacional foi firmemente externalizada ainda no final da década de 1940.

Naquele momento, previa-se instituir uma "Organização Internacional do Comércio (OIC)", no contexto do pós II Guerra Mundial. Dentre os temas em discussão, estava a temática de agricultura. Um dos pontos cruciais que levou ao fracasso das negociações para criação da OIC foi o fato de os EUA terem se recusado a abdicar de suas políticas agrícolas tal como vinham praticando $^{34}$.

No lugar daquela organização, então, foi instituído apenas o GATT. Firmado por um número relativamente restrito de países (o qual foi ampliado apenas com o passar das décadas), o seu conteúdo representava somente o que deveria ter sido apenas um dos "capítulos" da OIC. Dessa forma, ficaram de fora diversos aspectos relacionados ao desenvolvimento e às necessidades dos países menos avançados ${ }^{35}$. Por sua vez, o sistema estabelecido permitiu a continuidade de uma política agrícola extremamente protecionista e baseada em elevados níveis de subsídios.

As Comunidades Europeias também tiveram um papel relevante na dificultação da consolidação de acordos para o comércio agrícola internacional que não estivessem diretamente alinhados aos objetivos de curto prazo da sua política agrícola interna ${ }^{36}$. Para sintetizar, destaca-se que foram elas que articularam juntamente com os EUA, a portas fechadas, a proposta de acordo agrícola durante a Rodada Uruguai que foi colocada aos demais membros da Organização como con

\footnotetext{
${ }^{33}$ Neste texto, está se utilizando o termo que desde 1995 é usado pela OMC, por razões legais, para se referir à União Europeia. WORLD TRADE ORGANIZATION. Member Information: The European Communities and the WTO. Disponível em: <http://www.wto.org/ english/theWTO_e/ countries_e/european_communities_e.htm>. Acesso em: 06 fev. 2008.

${ }^{34}$ HUDEC, Robert E. The GATT legal system and world trade diplomacy. New York: Praeger, 1975. p. 63-65.

${ }^{35}$ ALMEIDA, Paulo Roberto. Relações internacionais e política externa do Brasil: história e sociologia da diplomacia brasileira. 2. ed. Porto Alegre: UFRGS, 2004. p. 116-117.

${ }^{36}$ HUDEC, op. cit., p. 201-202.
} 
dição para se ter um acordo geral. Esse episódio ficou conhecido como o acordo de "Blair House" ${ }^{37}$.

O projeto para a área agrícola daí resultante muito diferia daquele que se tentava negociar a partir do documento apresentado pelo então DiretorGeral do GATT, Arthur Dunkel, em fins de $1991^{38}$. Assim, ao menos no histórico, evidencia-se que as grandes potências econômicas Estados Unidos e Comunidades Europeias, na definição dos princípios e regras para o comércio agrícola internacional, buscaram estabelecer soluções talhadas ao atendimento das suas necessidades específicas.

Assim como o espírito geral da OMC como um todo, o Acordo sobre Agricultura multilateral trabalha com um grande objetivo central, que é promover a redução progressiva das barreiras ao comércio mundial e uma constante limitação das capacidades dos Estados nacionais de adotarem políticas quaisquer que interfiram no livre funcionamento do mercado ${ }^{39}$.

Ao se instituir, portanto, esse acordo, o que se promoveu foi justamente uma redução do grau de soberania dos 117 Membros signatários ${ }^{40}$, movimento contrário ao que se pretendia com o princípio de soberania alimentar consolidado na Lei Orgânica de Segurança Alimentar do Brasil. No entanto, essa limitação das soberanias nacionais absolutas teria, em princípio, ocorrido em nome de um sistema de comércio internacional teoricamente mais justo, equilibrado e benéfico para todos. Essa explicação se assemelha, portanto, ao que previam as teorias contratualistas clássicas ${ }^{41}$ em relação aos indivíduos dentro de uma sociedade que abdicariam de suas liberdades individuais absolutas e se sujeitariam a um conjunto de regras de convivência com outros para que se alcançasse uma situação com um resultado final mais benéfico para todos.

${ }^{37}$ Local em que EUA e Comunidades Europeias se reuniram para delinear a proposta de acordo.

${ }^{38}$ LACARTE MURÓ, Julio A. Ronda Uruguay del GATT: la globalización del comercio mundial. Montevidéu: Fundación de Cultura Universitaria, 1994. p. 142.

${ }^{39}$ ORGANIZAÇÃO MUNDIAL DO COMÉRCIO. The WTO in Brief. Genebra: OMC, 2007.

${ }^{40}$ Em agosto de 2008 este número já havia aumentado para 153.

${ }^{41}$ Suas principais raízes podem ser encontradas em Thomas Hobbes, John Locke e JeanJacques Rousseau. 
O que se verifica na prática, no entanto, é que os pedaços das soberanias nacionais absolutas que foram abdicados em decorrência das normas multilaterais do Acordo sobre Agricultura da OMC foram bastante desiguais entre os diferentes países. Quando se avalia mais de perto o conjunto de compromissos estabelecidos no Acordo, percebe-se que os países desenvolvidos, especialmente os Estados Unidos e as Comunidades Europeias, ficaram com uma margem muito maior que os demais para implementação de suas políticas públicas internas de apoio à agricultura, gestão do abastecimento e garantia da segurança alimentar nacional.

Enfim, antes de ser uma regra justa, construída com base em princípios concebidos em uma situação como a da "posição original" idealizada por John Rawls ${ }^{42}$, os limites às soberanias alimentares nacionais impostos pelo Acordo sobre Agricultura da OMC foram o resultado concreto de um exercício claro do poder de barganha que os países de maior peso econômico gozam no processo negociador do sistema de econômico multilateral.

Mesmo existindo elementos de "Tratamento Especial e Diferenciado" para os países em desenvolvimento ao longo do texto do Acordo, as bases gerais a partir das quais foram definidos os compromissos centrais (ou margens de política nacional) de cada país foram completamente desiguais. Isso gerou um resultado perverso em que todos os países tiveram que abrir mão de parte de suas soberanias, porém uns continuaram mais soberanos do que outros.

Essa percepção fica bem ilustrada na comparação dos montantes máximos de subsídios agrícolas domésticos autorizados pelo Acordo sobre Agricultura da OMC respectivamente ao Brasil e aos Estados Unidos para serem concedidos aos seus setores agropecuários.

Os subsídios agrícolas domésticos, ou Apoio Interno, como é conhecido nas discussões sobre agricultura no âmbito da OMC, em termos gerais, são categorizados de acordo com o grau de "distorcibilidade ao comércio" que apresentam. Em outras palavras, de acordo com o grau em que, segundo a OMC, mais afetariam

\footnotetext{
${ }^{42}$ Sobre a idéia da "posição original" de Rawls, ver: RAWLS, John. Uma teoria da justiça. 2. ed. São Paulo: M. Fontes, 2002. p. 19-24, cap. 3. (Coleção Justiça e Direito). Ver também: RAWLS, John. Justiça como equidade: uma reformulação. São Paulo: M. Fontes, 2003. p. 20-25, cap. 3. (Coleção Justiça e Direito).
} 
a liberdade dos demais países em terem acesso a um mercado mais livre e equilibrado ${ }^{43}$, propósito geral da própria Organização. Assim, os subsídios considerados mais distorcivos deveriam ser os mais firmemente restringidos. Isso porque o benefício obtido com o seu uso geralmente ocorre à custa de prejuízos para os demais países.

Desse modo, foram definidas cinco categorias de subsídios agrícolas domésticos, em uma relação que vai do menos ao mais "distorcivo". As cinco categorias são: a "caixa verde", as "medidas de desenvolvimento", a "caixa azul", o nível "de minimis" de apoio, e a "caixa amarela".44

Em valores monetários, o montante total de subsídios internos distorcivos que cada país membro está autorizado a aplicar em agricultura pode ser calculado por meio de uma medida agregada chamada "OTDS" (sigla em inglês que corresponde a "Overal Trade-Distorting Domestic Support", ou "Apoio Interno Total Distorcivo ao Comércio", traduzindo para o português). Ela concentra os subsídios mais distorcivos, da "caixa amarela", associados ao apoio de "caixa azul" e aos níveis "de minimis", de pequena escala. A "caixa verde" e as "medidas de desenvolvimento" ficam de fora do cálculo do OTDS por terem menos efeitos indesejados e não estarem sujeitas a compromissos de redução do apoio.

\section{Exemplo prático de (in) justiça}

Para trabalhar esse exemplo prático da medida de justiça (ou injustiça) do estabelecimento de compromissos no âmbito do Acordo sobre Agricultura da

\footnotetext{
${ }^{43}$ Nota-se que estes seriam objetivos manifestos da OMC. Pascal Lamy, atual Diretor-Geral da organização, enfatizou, em seu discurso durante o processo de seleção para o cargo, a necessidade de a Organização atuar cada vez mais nesse sentido, promovendo um mercado livre e equitativo, com regras semelhantes aplicáveis a todos. LAMY, Pascal. WTO Director-general selection process 2005: statement by Pascal Lamy. Disponível em: <http:// www.wto.org/ english/thewto_e/dg_e/ stat_lamy_e.htm>. Acesso em: 09 fev. 2008.

${ }^{44}$ WORLD TRADE ORGANIZATION. Agriculture: explanation. Domestic Support. Disponível em: <http:// www.wto.org/english/tratop_e/agric_e/ag_intro03_domestic_e.htm>. Acesso em: 10 fev. 2008. WORLD TRADE ORGANIZATION. Agriculture Negotiations: Background Fact Sheet. Domestic Support in Agriculture. The Boxes. Disponível em: <http://www.wto.org/english/tratop_e/agric_e/ agboxes_e.htm>. Acesso em: 10 fev. 2008. WORLD TRADE ORGANIZATION. Understanding the WTO. Third Edition. Geneva: WTO, 2007. p. 28-29.
} 
OMC, será feito aqui um contraste entre os níveis totais de apoio interno agrícola distorcivo permitidos por essa organização respectivamente aos EUA e ao Brasil. Esses níveis totais atuais são resultantes dos compromissos instituídos ao final da Rodada Uruguai, em 1994, quando foi firmado o Acordo sobre Agricultura atualmente em vigor ${ }^{45}$. A escolha dos dois países se deve ao fato de serem ambos de grande porte, exportadores agrícolas mundiais, porém, de situações sociais e econômicas completamente diferentes e desiguais (um em relação ao outro).

Vejamos antes alguns dados comparativos dos dois países. O primeiro, os EUA, ocupa uma área total de 9,3 milhões de quilômetros quadrados. Ele é a maior potência econômica do mundo, com um Produto Interno Bruto (PIB) absoluto de US\$ 12,5 trilhões. Seu PIB per capta é de US\$ 41,8 mil por habitante. É considerado um país de altíssimo nível de desenvolvimento. Seu Índice de Desenvolvimento Humano (IDH) é de 0,94 e a sua taxa de mortalidade infantil é de apenas 6,9 por cada mil nascidos. Os EUA têm uma população total de 298 milhões de habitantes, no entanto, a sua população agrícola corresponde a apenas $1,9 \%$ da população. Isso representa um total absoluto de 5,7 milhões de pessoas envolvidas com a atividade no meio rural. Já o Brasil, é também um país de grande porte em termos de território. Sua área total equivale a 8,5 milhões de quilômetros quadrados, apenas um pouco menor que o território dos EUA. No entanto, seus números econômicos e de desenvolvimento são muito mais modestos.

Como afirmado acima, a desproporção fica clara quando observamos os seguintes dados. Primeiramente, o PIB brasileiro é de apenas US\$ 799 bilhões. Isso corresponde a ínfimos 6,4\% do tamanho do PIB dos EUA. Já o PIB per capta do Brasil não ultrapassa US\$ 4,3 mil por habitante. O Brasil é ainda um país em via de desenvolvimento e enfrenta situações de fome e de pobreza no campo e no meio urbano. Seu IDH é de 0,79 e a taxa de mortalidade infantil é ainda alta, quando comparada com a dos EUA. Ela alcança no país 27,4 em cada mil nascidos, ou seja, é $297 \%$ maior que a dos EUA. A população total do país sul-americano é de 186 milhões de habitantes. Já a sua população agrícola corresponde a 25,8 milhões de pessoas. Portanto, diferentemente dos EUA; aqui, 13,8\% da população dependem da renda gerada no campo. A síntese dos números acima está consolidada na tabela que segue.

${ }^{45}$ No ano de 2008. 
Tabela - Dados comparativos dos EUA e do Brasil

\begin{tabular}{|l|l|l|}
\hline & \multicolumn{1}{|c|}{ EUA } & \multicolumn{1}{c|}{ Brasil } \\
\hline Área & 9,3 milhões de $\mathrm{Km}^{2}$ & 8,5 milhões de $\mathrm{Km}^{2}$ \\
\hline PIB absoluto & US\$ 12,5 trilhões & US\$ 799 bilhões \\
\hline PIB per capta & US\$ 41,8 mil por pessoa & US\$ 4,3 mil por pessoa \\
\hline IDH & 0,94 & 0,79 \\
\hline $\begin{array}{l}\text { Taxa de mortalidade } \\
\text { infantil }\end{array}$ & 6,9 por mil nascidos & 27,4 por mil nascidos \\
\hline População total & 298 milhões & 186 milhões \\
\hline População agrícola & 5,7 milhões & 25,8 milhões \\
\hline $\begin{array}{l}\text { População agrícola } \\
\text { (\% da população total) }\end{array}$ & $1,9 \%$ & $13,8 \%$ \\
\hline
\end{tabular}

Fonte: IBGE e FAOSTAT/FAO, ano 2005 (exceto IDH, cujos dados referem-se a 2003).

Olhando apenas o regulamento do Acordo sobre Agricultura da OMC frio, sem ver os números concretos dos compromissos individuais estabelecidos para cada país, poderíamos eventualmente ser levados a acreditar que, em princípio, pareceria haver certa equidade geral na Organização ${ }^{46}$. No entanto, quando entramos em números concretos, percebemos que o sistema de comércio equilibrado e justo previsto pela OMC parece ficar comprometido. Verifica-se então que foram estabelecidos efetivamente graus de soberanias desiguais.

A questão é que o ponto de partida ou a base a partir da qual se estabeleceram os compromissos dos diferentes países, é completamente desigual. E não é uma desigualdade estabelecida para favorecer os mais vulneráveis, social e economicamente mais frágeis. Ao contrário, é uma desigualdade que pende para o lado dos mais fortes. Há uma nitidez do "poder de ameaça" que foi utilizado durante a Rodada Uruguai, e que acaba contaminando as Rodadas negociadoras posteriores. Nesse sentido, a comparação de números de OTDS abaixo nos traz elementos da medida desse desbalanço.

\footnotetext{
${ }^{46}$ Regras de compromissos horizontais, com tratamento diferenciado para países em desenvolvimento.
} 
Os recentemente calculados níveis de OTDS, ou subsídios totais distorcivos em agricultura, permitidos para os EUA e para o Brasil, são bastante diferentes $^{47}$. De forma surpreendente, a autorização que a OMC dá àquele primeiro país para aplicar esse conjunto de subsídios distorcivos é $268 \%$ superior à dada ao Brasil. O OTDS dos EUA soma US $\$ 48,2$ bilhões, ao passo que o do Brasil é de apenas US\$13,1 bilhões. Ou seja, os EUA podem subsidiar (distorcivamente) um montante que é quase 4 (quatro) vezes o valor total que pode ser aplicado pelo Brasil para os mesmos tipos de subsídios.

Já quando se compara os números de autorização para subsídios especificamente de "caixa amarela", os considerados mais distorcivos de todos, a desproporção é ainda mais séria. O tamanho da diferença chega a ser de 20 (vinte) vezes em favor dos EUA. São US\$19,1 bilhões contra irrisórios US\$ 912 milhões do Brasil (números estes compreendidos dentro do valor agregado global do OTDS). O porquê dessa diferença é que a definição dos montantes de subsídios de "caixa amarela" autorizados para cada país foi quase que uma simples consolidação dos níveis que já vinham sendo historicamente praticados ${ }^{48}$.

${ }^{47}$ OTDS EUA: Total $=$ US\$ 48,2 bilhões. (Sendo US\$ 19,1 bilhões de "caixa amarela" e US\$ 29,1 bilhões do somatório da "caixa azul" e dos níveis "de minimis" específico e nãoespecífico por produto).

OTDS Brasil: Total = US\$13,1 bilhões (Sendo US\$ 912 milhões de "caixa amarela" e US\$ 12,2 bilhões do somatório da "caixa azul" e dos níveis "de minimis" específicos e nãoespecíficos por produto).

A forma de cálculo do OTDS utilizada aqui pode ser encontrada em: WORLD TRADE ORGANIZATION. Revised Modalities for Agriculture. TN/AG/W/4/Rev. 1. Committee on Agriculture. Special Session. 8 February 2008. Disponível em <http://www.wto.org/ english/tratop_e/agric_e/agchairtxt_feb08_e.pdf >. Acesso em: 10 fev. 2008.

${ }^{48} \mathrm{Na}$ Rodada Uruguai, o que se fez em essência foi apenas consolidar, para autorizações de subsídios futuros de "caixa amarela", os níveis desse tipo de subsídio que já haviam sido praticados, em média, pelo próprio país durante o período de 1986-1988. Os países desenvolvidos foram requeridos então a fazer um corte de $20 \%$ sobre esses níveis e os países em desenvolvimento de ate $13 \%$. WORLD TRADE ORGANIZATION. Understanding the WTO. Third Edition. Geneva: WTO, 2007, p. 28-29. Nota-se, no entanto, que o suposto "tratamento especial e diferenciado" concedido aos países em desenvolvimento (cortes percentuais menores dos níveis de subsídios) nem de longe foi suficiente para evitar uma situação de total desequilíbrio que permite ainda hoje, depois de mais de 10 anos da Rodada, a permanência de uma desproporção de US\$19,1 bilhões (EUA) para US\$ 912 milhões (Brasil) autorizados. Ou seja, uma diferença de cerca de dois mil por cento, em benefício do país desenvolvido. 
Nesse caso da "caixa amarela" dos EUA, mesmo ela sofrendo um corte hoje, por exemplo, de $80 \%$, e o Brasil continuando com o mesmo patamar atualmente autorizado, ainda assim continuaria um desnível significativo. No caso, de quase $320 \%$ de autorização superior para os EUA. Portanto, verifica-se um grave desequilíbrio que fica carente de justificação.

Poder-se-ia, então, adotar uma postura de reflexão com base em uma concepção de uma “posição original”, similar à formulada por John Rawls. Nesse caso, seria difícil de acreditar que seria possível se chegar um acordo que, em última instância, possibilitasse o funcionamento de um sistema que autorizasse uma diferença tão grande como a verificada entre as possibilidades de subsídios de EUA e Brasil ${ }^{49}$. Se o acordo inicial fosse feito em uma situação em que os membros representativos estivessem sob um "véu da ignorância" ${ }^{50}$, e, considerando que os princípios daí resultantes fossem efetivamente aplicados, os critérios para a definição dos montantes de subsídios tenderiam a ser diferentes dos que são atualmente verificados.

Recorda-se que, numa situação similar à pensada por Rawls, os países representativos desconheceriam quais as posições futuras que ocupariam no sistema. Assim, não saberiam quais seriam as suas capacidades econômicas ou o seu nível social de desenvolvimento. Por fim, não saberiam quais os níveis históricos de subsídios que cada um já teria praticado no passado. Seria algo como se os negociadores (pessoas representantes de governo), no momento do acordo inicial, não soubessem qual o governo do país a que pertencem. Ou seja, ao final da negociação, e levantado o "véu da ignorância", aquele negociador poderia acabar se descobrindo um senegalês, ou neozelandês, um membro das Comunidades Europeias ou um cubano. Qual seria então o critério mais equânime para a definição dos níveis de subsídios distorcivos que cada um seria autorizado a aplicar?

Racionalmente, portanto, os princípios que deveriam ser definidos na posição original seriam aqueles que levassem a uma definição futura de regras que se aproximasse o máximo possível do justo. Um representante de um governo, "sob um véu da ignorância", não poderia acordar algo que possibilitasse que

\footnotetext{
${ }^{49} \mathrm{E}$ que é verificada também em relação a diversos outros países membros da Organização.

${ }^{50}$ Elemento hipotético para auxílio a uma reflexão racional equânime, previsto por Rawls, conforme visto no começo deste texto.
} 
níveis de subsídios pudessem ser definidos com base simplesmente na prática ou capacidade histórica ou corrente de cada governo em subsidiar. Pois, caso o fizesse, poderia correr o risco de acabar caindo como representante dos EUA ou como representante da Botsuana.

O que seria justo de ser aplicado equitativamente aos dois casos? Assim, os princípios que norteariam as construções das regras tenderiam a ser outros, diferentes das práticas atuais do Acordo sobre Agricultura da OMC.

Para dar um exemplo didático, é possível fazer um exercício de limitação do montante total de subsídios internos distorcivos autorizados aos EUA - o seu OTDS -, em agricultura, como uma função do tamanho dos subsídios de mesmo tipo autorizados atualmente para o Brasil. No entanto, ao invés de usarmos os critérios atuais para ponderação da diferença, façamos uso de outro critério.

Utilizemos um critério que talvez fizesse mais sentido se o fossemos escolher a partir de princípios mais equitativos. Por um lado, trabalhar com o valor bruto total das produções agropecuárias dos dois países não tenderia a parecer o mais adequado. Isso porque geraríamos uma grande distorção em relação à quantidade efetiva de pessoas que poderiam estar recebendo o "benefício" dos subsídios. Assim, como forma de dar um maior grau de equidade, trabalhemos então, para estas simulações, com um critério mais centrado nas pessoas.

Uma primeira idéia poderia ser, então, autorizar os montantes de subsídios internos distorcivos de cada país em relação à quantidade de pessoas a serem alimentadas nele. Outra ideia, talvez até mais interessante, poderia ser limitar o tamanho desses subsídios em relação ao tamanho da população agrícola do país em questão. Nesse caso, o montante de subsídios distorcivos seria autorizado em relação ao quantitativo de pessoas efetivamente envolvidas com a atividade agropecuária. Vejamos como ficariam os níveis de subsídios distorcivos dos EUA em proporção ao Brasil nesses dois casos.

Na primeira situação, utilizaríamos os números totais de habitantes do Brasil e dos EUA. Respectivamente, estes seriam de 186 e 298 milhões de pessoas. Em termos proporcionais, portanto, a população dos EUA equivale a $160 \%$ da população brasileira. Então, a quantidade de pessoas a serem ali- 
mentadas nos EUA é $60 \%$ maior que no Brasil. Assim, utilizando essa medida, o montante máximo de subsídios distorcivos passível de ser dado pelos EUA seria até $60 \%$ superior ao hoje permitido para o Brasil. Isso sem considerar ainda nenhum tipo de tratamento especial e diferenciado em favor dos países em desenvolvimento. Os novos limites de OTDS, em proporção direta, então, ficariam conforme a tabela que segue:

\section{Limites para subsídios internos totais distorcivos em agricultura (OTDS) - Exercício 1}

\begin{tabular}{|l|l|l|}
\hline & \multicolumn{1}{|c|}{ Nível atual } & \multicolumn{1}{|c|}{$\begin{array}{c}\text { Com critério de } \\
\text { pessoas a alimentar }\end{array}$} \\
\hline Brasil $^{*}$ & US\$ 13,1 bilhões & US\$ 13,1 bilhões \\
\hline EUA & US\$ 48,2 bilhões & US\$ 21,0 bilhões \\
\hline$\%$ EUA / Brasil & $368 \%$ & $\mathbf{1 6 0 \%}$ \\
\hline
\end{tabular}

* País de referência

A segunda situação seria adotar como base de ponderação o quantitativo efetivo de pessoas diretamente envolvidas com a atividade agrícola em cada país. Para esse caso, o dado do Brasil correspondente é de 25,8 milhões de pessoas. Já nos EUA, o número absoluto de pessoas na área agrícola é de apenas 5,7 milhões. Assim, verificamos que a população agrícola dos EUA equivale apenas a 22\% daquela existente no Brasil. Considerando o volume de subsídios distorcivos que os EUA têm tido autorização para aplicar, segundo o regulamento corrente da OMC, podemos tirar uma conclusão relevante: o volume de subsídio distorcivo per capta, por pessoa envolvida com a atividade agrícola, autorizado por essa organização aos EUA hoje, é extremamente superior ao que a mesma organização permite ao Brasil. Vejamos abaixo como ficaria o limite de OTDS dos EUA, se ponderado diretamente pela sua população agrícola em relação ao tamanho da população agrícola do Brasil: 


\section{Limites para subsídios internos totais distorcivos em agricultura (OTDS) - Exercício 2}

\begin{tabular}{|l|l|l|}
\hline & \multicolumn{1}{|c|}{ Nível atual } & \multicolumn{1}{|c|}{$\begin{array}{c}\text { Com critério da } \\
\text { população agrícola do } \\
\text { país }\end{array}$} \\
\hline Brasil $^{\star}$ & US\$ 13,1 bilhões & US\$ 13,1 bilhões \\
\hline EUA & US\$ 48,2 bilhões & US\$ 2,9 bilhões \\
\hline$\%$ EUA / Brasil & $368 \%$ & $\mathbf{2 2 \%}$ \\
\hline
\end{tabular}

* País de referência

Como mencionado acima, no cenário atual, cada uma das 5,7 milhões de pessoas da área agrícola dos EUA tem direito a um subsídio distorcivo médio anual de US\$ 8,4 mil. Já para o Brasil, com população agrícola de 25,8 milhões, essa autorização média é de insignificantes US\$ 508 para cada. No novo cenário, com base no critério de limitação do OTDS em função do tamanho da população agrícola do país, ambos teriam uma autorização de subsídio médio de US\$ 508 por pessoa. Isto considerando uma proporção direta. Se for seguir de forma estrita a orientação de maior benefício aos socioeconomicamente menos favorecidos - presente tanto nos princípios da OMC quanto no princípio de justiça da “igualdade” previsto por Rawls - , ainda ter-se-ia que adicionar algum tipo de desvio da proporção direta em favor do país em desenvolvimento.

Essas análises simulatórias, portanto, dão-nos elementos para ter uma ideia do grau de justiça (ou injustiça) com o qual trabalha hoje o Acordo sobre Agricultura da OMC no aspecto da autorização para os subsídios internos distorcivos em agricultura. Fica claro que a margem de política pública autorizada para os EUA, ou o seu grau de soberania em termos de políticas para o setor agropecuário e alimentar, é significativa e desproporcionalmente maior que aquela concedida ao Brasil.

\section{Conclusão}

Como foi observado, o processo de discussão interno brasileiro tem dado uma crescente ênfase à perspectiva da soberania alimentar como sendo um elemento importante para a consecução do direito à alimentação da população. Esse processo 
de discussão culminou, inclusive, com a formalização dessa perspectiva no texto da uma lei, a Lei Orgânica de Segurança Alimentar e Nutricional (LOSAN).

A soberania alimentar é entendida como a manutenção, frente aos compromissos firmados no âmbito internacionais, de margens nacionais para aplicação de políticas públicas relativas ao fomento à produção de alimentos e à definição do sistema de abastecimento e acesso aos alimentos. Já o Acordo sobre Agricultura da OMC trabalha, por princípio, com uma lógica significativamente oposta. Esse acordo visa promover justamente reduções progressivas das margens de políticas públicas nacionais, de forma a possibilitar, em teoria, um funcionamento do sistema de produção e comércio mundial de alimentos da forma mais livre possível, sem interferência dos Estados nacionais.

Com o exemplo prático dos limites de recursos que o Acordo sobre Agricultura da OMC autoriza para Brasil e Estados Unidos utilizarem com políticas públicas de incentivo interno, verificam-se fortes indícios de que o sistema de comércio multilateral atual estabelece restrições às soberanias alimentares nacionais de forma diferenciada, e que, ao fazê-lo, estabelece graus de soberania alimentar mais elevados a países que, em princípio, menos precisariam deles. Em síntese, com o Acordo sobre Agricultura da OMC, todos têm que abrir mão de parte de suas soberanias, porém, uns permanecem mais soberanos que outros.

\section{Principles of the brazilian food security policy and the agreement on agriculture of the WTO}

\section{Abstract}

This article intends to underline that there is a contradiction between the goal intended by the core principle of the Agreement on Agriculture of the World Trade Organization (WTO) and those defined by the Organic Law on Food Security of Brazil (OLFS), and also an issue of injustice regarding the developing countries. While the OLFS emphasizes the importance of the 
preservation of the capacity of the national States to define their own policies for food production incentive, the Agreement on Agriculture leads all Member States of that organization to have to relativize their degree of sovereignty in terms of food. This relativization, however, occurs in an unbalanced way, in favor of developed countries, specially the United States and the European Union, which had a protagonist role on the drafting of the Agreement on Agriculture currently in force.

Keywords: Food sovereignty. Agreement on Agriculture. WTO(World Trade Organization).

\section{Referências}

ALMEIDA, Paulo Roberto. Relações internacionais e política externa do Brasil: história e sociologia da diplomacia brasileira. 2. ed. Porto Alegre: UFRGS, 2004.

BARRAL, Welber (Org.). O Brasil e a OMC. 2. ed. Curitiba: Juruá, 2002.

BELIK, Walter. Segurança alimentar: a contribuição das universidades. São Paulo: Instituto Ethos, 2003.

BRASIL. Lei no 11.326 , de 24 de julho de 2006. Estabelece as diretrizes para a formulação da Política Nacional da Agricultura Familiar e Empreendimentos Familiares Rurais. Diário Oficial da União, Brasília, 25 jul. 2006.

Lei no 11.346 , de 15 de setembro de 2006. Cria o Sistema Nacional de Segurança Alimentar e Nutricional - SISAN com vistas em assegurar o direito humano à alimentação adequada e dá outras providências. Diário Oficial da União, Brasília, 18 set. 2006.

Medida provisória $\mathrm{n}^{\circ}$ 103, de 01 de janeiro de 2003. Dispõe sobre a organização da Presidência da República e dos Ministérios, e dá outras providências. Diário Oficial da União, Brasília, 01 jan. 2003.

- Ministério do Desenvolvimento Agrário. Desenvolvimento agrário como estratégia: balanço MDA 2003-2006. Porto Alegre: Nead, 2006.

. Mais alimentos: um plano da agricultura familiar para o Brasil. Plano Safra da Agricultura Familiar 2008/09. Brasília: MDA, 2008. 
CONFERENCIANACIONALDESEGURANÇA ALIMENTARENUTRICIONAL, 2., 2004, Olinda, PE. A construção da Política Nacional de Segurança Alimentar e Nutricional - Relatório Final. Disponível em: <http://www. fomezero.gov.br/ download/relatorio_final_IICNSAN.pdf>.Acesso em: 15 maio 2006.

CONSELHO NACIONAL DE SEGURANÇA ALIMENTAR E NUTRICIONAL. Considerações de segurança alimentar e nutricional nas negociações internacionais integradas pelo Brasil - Relatório final. Brasília, 2005.

2006.

. Lei de segurança alimentar e nutricional: conceitos. Brasília: CONSEA,

DELGADO, Nelson Giordano; MALUF, Renato S. Comércio e desenvolvimento no acordo sobre agricultura da OMC: O Brasil e a proposta de uma caixa de desenvolvimento. In: AGRICULTURA, meio ambiente e acesso ao mercado internacional: para quê e para quem? Rio de Janeiro: Action Aid, 2002.

FAO. The State of Food Insecurity in the World 2006: eradicating world hunger - taking stock ten years after the World Food Summit. Roma: FAO, 2006.

FAO, 2003.

. Trade reforms and food security: conceptualizing the linkages. Roma:

HUDEC, Robert E. The GATT legal system and world trade diplomacy. New York: Praeger, 1975.

IPEA; SEDH; MRE. A segurança alimentar e nutricional e o direito humano à alimentação no Brasil. Brasília: IPEA, 2002.

LACARTE MURÓ, Julio A. Ronda Uruguay del GATT: la globalización del comercio mundial. Montevidéu: Fundación de Cultura Universitaria, 1994.

LAMY, Pascal. WTO Director-general selection process 2005: statement by Pascal Lamy. Disponível em: <http://www.wto.org/english/thewto_e/dg_e/ stat_lamy_e.htm>. Acesso em: 09 fev. 2008.

MOTA, Dalva Maria da; SCHMITZ, Heribert. Importância da agricultura familiar para a problemática da segurança alimentar. Estudos: Revista da Universidade Católica de Goiás, Goiânia, v. 32, n. 2, 2005.

RAWLS, John. Justiça como equidade: uma reformulação. São Paulo: Martins Fontes, 2003. (Coleção Justiça e Direito). 
. Uma teoria da justiça. 2. ed. São Paulo: Martins Fontes, 2002. (Coleção Justiça e Direito).

ROCHA, Sônia; ALBUQUERQUE, Roberto Cavalcanti de. Geografia da pobreza extrema e vulnerabilidade à fome. In: VELLOSO, João Paulo dos Reis; ALBUQUERQUE, Roberto Cavalcanti de (Org.). A nova geografia da fome e da pobreza. Rio de Janeiro: J. Olímpio, 2004.

SÍCOLI, Juliana Lordello. Pactuando conceitos fundamentais para construção de um sistema de monitoramento da SAN. [s.l.]: Instituto Polis, 2005. p. 7. Disponível em: $<$ http://www.polis.org.br/download/65.pdf >. Acesso em: 25 maio 07.

SOARES, Adriano Campolina. Multifuncionalidade da agricultura familar. In s. Rio de Janeiro: Rebrip / Action Aid, 2001.

SOUTH CENTRE. Policy space for the development of the south. 'T.R.A.D.E. policy brief'. n. 1, 2005. Disponível em: <http://www.southcentre.org/info/ policybrief/01PolicySpace.pdf>. Acesso em: 25 mai.2007.

. Universal food security: issues for the south. Genebra, 1997, p. 68. Disponível em: <http://www.southcentre.org/publications/food/foodsec.pdf > . Acesso em: 28 mai. 2007.

TAKAGI, Maya. A implantação da política de segurança alimentar e nutricional no Brasil: seus limites e desafios. Campinas: Unicamp/IE, 2006.

WORLD TRADE ORGANIZATION. Agriculture: explanation. Domestic support. Disponível em: <http://www.wto.org/english/tratop_e/agric_e/ag_intro03_ domestic_e.htm>. Acesso em: 10 fev. 2008.

Agriculture Negotiations: background fact sheet. Domestic support in agriculture. The boxes. Disponível em: <http://www.wto.org/english/tratop_e/ agric_e/agboxes_e.htm>. Acesso em: 10 fev. 2008.

- Member Information: The European Communities and the WTO. Disponível em: <http://www.wto.org/english/theWTO_e/countries_e/european_ communities_e.htm>. Acesso em: 06 fev. 2008.

Revised Modalities for Agriculture. TN/AG/W/4/Rev.1. Committee on Agriculture. Special Session. 8 Feb. 2008. Disponível em <http://www.wto.org/ english/tratop_e/agric_e/agchairtxt_feb08_e.pdf >. Acesso em: 10 fev. 2008. 

280 | Prismas: Dir., Pol. Publ. e Mundial., Brasília, v. 5, n. 2, p. 255-280, jul./dez. 2008
Rafael Rosa Cedro

. The World Trade Organization in Brief. p. 3-4. Disponível em: <http:// www.wto.org/english/res_e/doload_e/inbr_e.pdf>. Acesso em: 30 jan. 08.

. Understanding the WTO. Third Edition. Geneva: WTO, 2007.

. Uruguay Round Agreement: Marrakesh Declaration of 15 April 1994. Disponível em <http://www.wto.org/english/docs_e/legal_e/marrakesh_ decl_e.htm>. Acesso em: 05 fev. 2008. 